International Review of Research in Open and Distributed Learning Volume 17, Number 1

January - 2016

\title{
Research Papers in Online Learning Performance and Behaviour
}

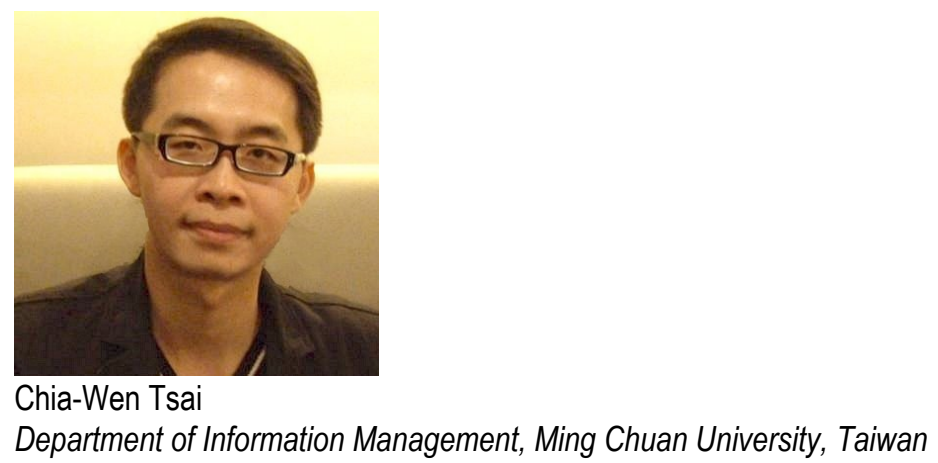

\section{Editorial - Volume 17, Issue Number 1}

Successful learning requires that students be motivated to achieve the desired learning goals (Lee, \& Hao, 2015). However, not all students can develop an effective path that is beneficial to learning on their own (Lee, Cheng, Rai, \& Depickere, 2005). The increasing popularity and number of online programs and course in higher education require continued attention to the design of instructional environments to enhance students' learning (Trespalacios, \& Rand, 2015). As there is a continuing debate about effective design of online learning environments (Azevedo, 2005) and effective teaching methods (Tsai, 2011a), researchers in the field of online learning and online pedagogy suggest that educators could integrate other innovative teaching methods into online courses and examine their effects on improving students' learning in online learning environments (Tsai, 2011b; Tsai, 2015). In this regard, this special issue was conceived to span pedagogical, theoretical, practical, and technical issues in online learning performance and behaviour.

The authors in this special issue present several approaches, tools, and applications of online learning and web-based learning technologies. This special issue features 12 papers that each underwent at least two rounds of review. 
As handheld devices are becoming popular and widely used, educators could use them as a primary channel to deliver knowledge. The article by Chen-Wei Hsieh and Sherry Y. Chen, A Cognitive Style Perspective to Handheld Devices: Customization vs. Personalization, reports on two empirical studies to explore the effects of cognitive styles on the use of a customized digital learning system (CDLS) and personalized digital learning system (PDLS). The two systems are implemented with handheld devices, as well as tailored to the needs of cognitively different groups. The article concludes with a description of students who are using CDLS and PDLS, and how those students received similar task scores and posttest scores, despite the students' differing cognitive styles.

In the following article titled Using Humorous Images to Lighten the Online Synchronous Learning Experience Through Questioning in Class, Chia-Hung Lai, Ming-Chi Liu, Chia-Ju Liu, and Yueh-Min Huang use in-class questions and propose to show students funny images to reward them for answering correctly. They note that participants' facial expressions indicate that funny images help to arouse positive emotions in the participants. In addition, the collected data on the electroencephalogram (EEG) responses reveals that the students receiving the rewards trended toward increasing levels of relaxation and attention.

When learning in an online course, students may have to complete their task by navigating via linked materials. The article by Johannes Naumann and Ladislao Salmerón, Does Navigation Always Predict Performance? Effects of Navigation on Digital Reading are Moderated by Comprehension Skills, demonstrates that the positive relationship between navigation and performance may be moderated by students' offline comprehension skills. The authors indicate the positive effects of offline comprehension skill and relevant page selection on digital reading performance.

Online collaboration and computer-supported collaborative learning (CSCL) are hot issues in the field of online education. Xusen Cheng, Xueyin Wang, Jianqing Huang, and Alex Zarifis's article, An Experimental Study of Satisfaction Response: Evaluation of Online Collaborative Learning introduces thinkLets to online collaborative learning, and empirically demonstrates its effectiveness on students' satisfaction. The authors in this paper indicate that participants feel more satisfied with the adoption and help of thinkLets in a Group Support System (GSS). This paper also provides references for designing online learning activities to achieve higher online collaborative learning quality.

The fifth paper, titled Analysis of Learning Achievement and Teacher-Student Interactions in Flipped and Conventional Classrooms, presented by Jerry Chih-Yuan Sun and Yu-Ting Wu, addresses and explores the effect that OpenCourseWare, integrated with flipped classrooms, has on student learning achievements and teacher-student interaction. Their findings report that students who used OpenCourseWare integrated with flipped classrooms scored higher in learning achievement. The authors also describe how the adoption of the flipped classroom model could have a positive effect on students' learning.

Jennifer LoCasale-Crouch, Bridget Hamre, Amy Roberts, and Kathy Neesen's paper titled If You Build It, Will They Come? Predictors of Teachers' Participation in and Satisfaction with the Effective Classroom 
Interactions Online Courses, introduces the design of Effective Classroom Interactions (ECI) online courses to enhance early childhood teachers' use of classroom practices that influence children's school readiness. This paper presents one of the first in-depth explorations of early childhood teachers' participation in two innovative online courses, intended to help other educators in this field to design effective teaching methods when training early childhood teachers.

In Challenges of Transitioning to e-Learning System with Learning Objects Capabilities, Miroslava Raspopovic, Svetlana Cvetanovic, and Aleksandar Jankulovic note the problem of budget constraints and transitional challenges when implementing blended and/or online learning. The authors of this paper indicate the advantages, disadvantages, and potential barriers of e-learning system implementation with learning objects (LOs). Moreover, the authors also provide an overview of suggestions for implementation improvements of LO oriented e-learning systems.

As students' learning performance in an online learning environment could be influenced by their readiness to adopt this innovative learning approach, the article by Muhammad Ayub Buzdar, Akhtar Ali, and Riaz Ul Haq Tariq, Emotional Intelligence as a Determinant of Readiness for Online Learning examines psychometric aspects of students' preparedness for online learning and explores their emotional intelligence as a determinant of readiness for online learning. The authors of this article reveal that emotional intelligence has a significant effect on learners' readiness for online learning. In addition, they also indicate both the potential and the need for adopting pedagogical strategies that foster students' emotional intelligence and other psychometric abilities to develop their readiness for online learning.

Janine M. Lim in, The Relationship between Successful Completion and Sequential Movement in SelfPaced Distance Courses demonstrates students' behavior to understand if the sequence of student assignment submissions in a self-paced distance course is related to the completion of the course. The author of this study finds that learners who completed at least one assignment or exam out of the intended sequence of instruction had higher potential to complete the self-paced distance course. It is also suggested by the author that learner control and self-direction within self-paced distance courses should be included in online course design.

The 10th, titled, Factors of Participants and Blogs that Predict Blogging Activeness during Teaching Practice and Induction Year by Piret Luik and Merle Taimalu, investigates factors that predict "blogging activeness." The results of their study reveal that the strength of social relationships among the participants in the blog and the participants' judgement that blogging was suitable are the most significant predictors of participant "activeness" in the blog. They also suggest that teachers could adopt blogs in their courses, and point out that blogs are still a growing trend in some countries, such as Estonia.

Online learning behaviors can be considered to be a predictor of students' final learning performance. The 11th paper titled, Evaluation of Online Log Variables that Estimate Learners' Time Management in a Korean Online Learning Context by Il-Hyun Jo, Yeonjeong Park, Meehyun Yoon, and Hanall Sung, aims to identify the relationship between the psychological variables and online behavioral patterns of 
students. The authors in this study report that students' online behavior related to time mediates their psychological functions and their learning outcomes. This paper could provide a reference for educators to have better understanding of how students manage their time when engaged in an online course.

In the last article in this special issue, titled An Empirical Study of Factors Affecting Mobile Wireless Technology Adoption for Promoting Interactive Lectures in Higher Education, Chin Lay Gan and Vimala Balakrishnan investigate the factors supporting the use of mobile wireless technology to promote interactivity between students and lecturers. Moving beyond previous research of technology acceptance, this study reflects a mind-set among young learners towards mobile applications, indicating that confidence, ease of use, and enjoyment in using mobile applications are tightly correlated.

As new information technology continues to advance, instructional designers could design relevant digital learning that may provide different types of learning resources or materials for students (Chen, Chiu, \& Huang, 2015). Teachers should adopt and integrate effective online teaching methods into online courses to help students achieve better learning performances. Moreover, teachers could even adopt digital games or social network games (O'Toole \& Lee, 2015) to engage learners, develop their motivation for learning, and further improve their learning performance. It is expected that the articles in this special issue can provide readers, educators, teachers, and schools that are implementing online education some references for design of their online, blended, or flipped courses, and further improve their students' learning performances and behaviours. Finally, the guest editor of this special issue would like to express appreciation to the reviewers for their constructive comments and suggestions that contributed to the completed versions of this issue's papers.

\section{References}

Azevedo, R. (2005). Using hypermedia as a metacognitive tool for enhancing student learning? The role of self-regulated learning. Educational Psychologist, 4O(4), 199-209.

Chen, C. C., Chiu, P. S. \& Huang, Y. M. (2015). The learning style-based adaptive learning system architecture. International Journal of Online Pedagogy and Course Design, 5(2), 1-10. doi:10.4018/IJOPCD.2015040101

Lee, C. H. M., Cheng, Y. W., Rai, S. \& Depickere, A. (2005). What affect student cognitive style in the development of hypermedia learning system? Computers \& Education, 45(1), 1-19.

Lee, L. C. \& Hao, K. C. (2015). Designing and evaluating digital game-based learning with the ARCS motivation model, humor, and animation. International Journal of Technology and Human Interaction, 11(2), 80-95. doi:10.4018/ijthi.2015040105 
O'Toole, E. \& Lee, S E. (2015). Using a social network game as a teaching tool for visual merchandising. International Journal of Online Pedagogy and Course Design, 5(3), 1-16.

doi:10.4018/ijopcd.2015070101

Trespalacios, J. \& Rand, J. (2015). Using asynchronous activities to promote sense of community and learning in an online course. International Journal of Online Pedagogy and Course Design, 5(4), 113. doi:10.4018/IJOPCD.2015100101

Tsai, C. W. (2011a). How much can computers and internet help? A long-term study of web-mediated problem-based learning and self-regulated learning. International Journal of Technology and Human Interaction, 7(1), 67-81.

Tsai, C. W. (2011b). Achieving effective learning effects in the blended course: A combined approach of online self-regulated learning and collaborative learning with initiation. Cyberpsychology, Behavior, and Social Networking, 14(9), 505-510.

Tsai, C. W. (2015). Applying web-based co-regulated learning to develop students' learning and involvement in a blended computing course. Interactive Learning Environments, 23(3), 344-355.

\section{Athabasca} University

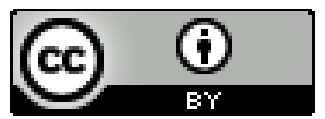

